\title{
The Influence of ERgonomics PARAMETers on ReAdy-MAde GARMENTS INDUSTRY \\ AN ANALYTical RESEARCH
}

Prof. Dr. Ahmed El-Tahan

Chairman of Readymade Garments Technology Dpt.

$X$-Vice Dean Of Research And Culture Affairs, Faculty Of Applied Arts, Damietta Univ., Egypt

\section{By}

Heba AbuEl-Nasr
Demonstrator In Readymade Garment
Department, Faculty Of Applied Arts,
Damietta Univ., Egypt

Research Gournal Specific Fducation

Faculty of Specific Fducation

Mansoura University

ISSUE NO. 35, JULY. 2014

مجلة بحوث التزبية النوعية - جامعة المنصورة

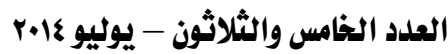




\title{
THE INFLUENCE OF ERGONOMICS PARAMETERS ON READY-MAde GARMENTS INDUSTRY \\ AN ANALYTICAL RESEARCH
}

\author{
Prof. Dr. Ahmed El-Tahan * Heba AbuEl-Nasr **
}

Abstract

The research shed lights on analysis the parameters of ergonomics relevant to the attributes of [cognitive, Engineering and technology] which contribute on improving the RMGI working system through fitting the integration between human/labor characteristics with his task, tools /machine and the industrial RMG environment. Research methodology depends on analyzing the parameters of ergonomics relevant to the identification challenges of RMGI. So, our paper is going to highlight the substantial related searches to ergonomics and one of its applications in the field of RMGI. Thus, the recent increase in research activity in this area and the positive results encourage the future development of such ergonomics intervention programs in the RMGI. The conclusions highlight the need to carry out intervention programs with its respect to ergonomics parameters to achieve optimization of work systems. The profession's goals are related to "humanization the RMGI, thus building ergonomics awareness is certainly the first phase of the ergonomic process ."

Keby Words :Apparel Manufacture, Ergonomic Practices, Norms of Clothing Industry and Ergonomics Solutions.

\section{- Introduction}

Ready-Made Garment Industry [RMGI] is one of the most important strategic industries which constitute about $7 \%$ of total industrial production in the world and $8.3 \%$ of the total trade in industrial materials. It occupies more than $14 \%$ of the total labour force in the world. It employs about 40 million people in various countries of the world. (Padmini S. and Venmathi A., 2012). The RMGI also remains an attractive issue for developing

Chairman of Readymade Garments Technology Dpt. X-Vice Dean Of Research And Culture Affairs, Faculty Of Applied Arts, Damietta Univ., Egypt

** Demonstrator In Readymade Garment Department, Faculty Of Applied Arts, Damietta Univ., Egypt 
countries like Egypt-garment production is low-capital and high-labor cost (Dan Magder, august 2005). Ergonomics has many contributes on any designed artefact, ranging from a consumer product to an organizational environment. Whenever Ergonomics does not play a role in a system design it could be lead to sub-optimal systems with quality deficits, reduced efficiency, illness, dissatisfaction, etc. whenever, Ergonomics can provide solutions to these problems (Jan Dula, R.B., and oth M ers, 2012).The influence of poor ergonomic features also had to a large extent, a negative impact on the production of garments. They came to the realization that ergonomics interventions could have a significant impact resulting in fewer errors, minimum time spent and improve the well-being and productivity. It also pays as an increase in output and will mean more income for the garment producer and corresponding improvement in their quality of life

\section{- Concept \& Definitions of Ergonomics}

The term ergonomics is derived from" Ergonomia "which was originally published in Poland in 1857 by a Polish engineer Dr. W. Jastrzebowski. The engineer and psychologist J.K.F. Murrel has been credited for the term" Ergonomics "in 1949. This was the name to be the basis of the discipline known as" Fitting the Task to the Man "(David C., 2007).

The International Ergonomics Association (2000) provides the following definition, in its triennial report:

"Ergonomics (or human factors) is the scientific discipline concerned with the understanding of interactions among humans and other elements of a system, and the profession that applies theory, principles, data and methods to design in order to optimize human well-being and overall system performance", (IEA Council, 2000).

Most definitions assure that Ergonomics is a Body of knowledge aims to design the best practices for matching the integration between characteristics, capabilities and limitations of human with his task, tools /machine and his environment . This is to maximize human productivity, comfort, usability, health, and safety, whilst Reduce injury, illness, and the likelihood of errors .[*]

\section{- Ergonomics Parameters [EP]}

It extends to the characteristics of the three key's concepts; cognitive, technology and engineering ergonomics which represent ergonomic challenges in RMGI. Do these characteristics appear its responsibility through the ergonomic solutions? 


\section{- Previous work}

Ergonomics, as a Recent application for RMGI, presents many new challenges to designers leading to create an ergonomically interventions.

A Master study centralizes around the sewing operator to suggest an ergonomically design for his sitting posture. It depends on the agents which affect performance efficiency on the operator. Even it explains the sewing tasks, workplace and Environmental conditions) Mai Samir, 2008 .(

In addition to, a field study was conducted on five factories in three Egyptian prefectures (Zainab and Abeer, 2009). The Research indicated that most diseases were turned back to an inconvenient design for (chairs - tricot tables - mishandling and workplace whilst no health care was encouraged .The research was reported as a feedback towards new solutions to implement for serving other search titled with "the ergonomic designing solutions to face the constraints of apparel industry in Egypt". They have been focused their efforts on three key-notes suggest:

- Designing sewing unit [sewing tables and chairs].

- Organizing track of production line .

- Designing The environment surrounding the workplace

[Handling - lighting - noise - ventilation] (Zainab, Hasn, et al., 2009)

\section{- Methodology}

The research methodology depends on gathering ergonomics parameters which represent the challenges in RMGI, and eventually analyzing its effect on RMGI.

\section{- Identification the challenges}

Studies have been using worksite analysis tools to identify the highrisk parameters which influence the RMG workers (David Mijatovic, 2008). However, to discuss any concerns and/or place a suggestion box in the plant for workers, direct meeting with labors has been done .

Thus the ergonomic problems have recorded as the most dominant factors found in RMGI as follows:

- Process and Operating sequence

- Productivity levels and quality

- work stoppages statistical 
- Materials and Product waste

- Resignations, Turnover and fresh workers

- Salaries and workforce

- Clinic statistics and Medical Assistant

- Repair of machinery records

- Contracts

- Training

- Internal Regulations

- Symptom survey results

\section{- Measurement \& Evaluation}

According to $\mathrm{OHCOW}$ 'to evaluate ergonomics parameters it must take measures before and after any action to be made. By measuring something that occurs with more frequency, an ergonomic change can be evaluated more quickly, and accurately. Careful inspection of these factors may reveal patterns that highlight priority areas and direct the investigation of RMG sectors. These measurements allow RMGI to stop accidents before it occurs.

\section{- Analytical view}

Ergonomics science can be categorized through three key concepts that characterize ergonomics parameters as :

Human characteristics (cognitive), Systems Integration (Technology managements) and Ergonomic Design (Engineering)

\section{- Cognitive Ergonomics [CE]}

CSs are natural or artificial information processing systems, including those responsible for perception, learning, reasoning, decision making for communication and action. CS can be summarized as an approach to the design of technology, training, and processes intended to manage cognitive complexity in sociotechnical systems (Laura G. Militello, et al. 2009.(

Usually, Information ergonomics comprises the analysis, evaluation and design of information systems. Those including the psychological components of the stakeholders (capabilities and preferences, etc.) as well as work tasks (information tasks) and working conditions (system and environmental conditions) .However attention be made with particular 
$\overline{\underline{ }}$

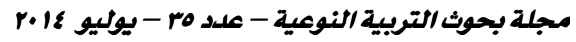

emphasis on the aspects of motivation, emotion and cognitive structure (content knowledge and media literacy (Michael S. and Peter S., 2012.(

\section{- Work tasks (information tasks)}

One important contribution by ergonomics is the distinction between prescribed work - better known as" tasks - "and actual work or" activity ، “ which is what the worker really performs within his or her job) "Juan C. Hiba .(

To describe the knowledge required for the performance of work tasks, it is necessary to use Cognitive Task Analysis (CTA.(

CTA is the extension of traditional task analysis techniques to yield information about the knowledge, thought processes and goal structures that underlie observable task performance. CTA uses a variety of interview and observation strategies to capture a description of the knowledge that experts use to perform complex tasks) Richard Clark, et al., 2006.(

\section{- Human capabilities and preferences}

According to (White Queen Safety Strategies \& Environmental Resources Management, 2007 (Cognitive processes have various capabilities such search, sensory memory, short term memory and working memory, long term memory and semantic memory knowledge representation, imagery, decision making and risk assessment problem solving and reasoning, learning, skill development, knowledge acquisition and concept attainment, language communication and comprehension, and reading .

\section{- Working conditions}

Decreasing the gap between human limitation and the work demands, lead to improve the working condition and help human to minimize fatigue, workload, number of errors, and work accident. Whist balance the working conditions require matching between three forces such work demands, human capabilities and physical environment (Wendy M., 2003). Managers in garment factories who recognize the potential to boost their bottom line by improving working conditions might not have accurate information on which investments to make. This incomplete understanding can perpetuate poor working conditions and undermine efforts of well-intentioned managers to improve factory conditions. For example, reform-minded 
managers faced with investing limited resources among competing priorities could boost wage rates and benefits, improve workplace safety or invest in workplace amenities, among others changes) ILO\& IFC, Dec 2013.(

\section{- The Technology of Ergonomics [TE]}

TE defined as the entire system of people and organizations(Waldemar K., 2006), knowledge, processes, and devices that go into creating and operating technological artifacts. It was also defined as the artifacts themselves; in particular to recognize those aspects of the technology that are flexible/changeable (BCPE, 2013)

At the 21 st century 'where labor is expensive, the use of technology in RMGI is ever increasing where technology has made manufacturing more capital-intensive and less labor-intensive. Thus, these new safety evoke this paper for taking an approach to analyze human factors interface technology of ready-made garment industry [RMGI]

There are two approaches that can be used in manufacturing today .

- One general approach, is the human-system interface technology (HSIT ،(was cited by Hendrick (2002) and contains components similar to that of the SHEL model, such:

- Human-Machine Interface Technology [Hardware Ergonomics.[

- Human/Environment Interface Technology. [Environmental Ergonomics[

- Human/Software Interface Technology [Cognitive Ergonomics.[

- Human/Job Interface Technology [Job Design Ergonomics.[

- Human/Organizational Interface Technology. [Macroergonomics.[

Once again, each of these components (with the exception of the fifth interface technology) was predominantly a micro-ergonomics approach, applied to enhance safety, health, comfort, and performance, including productivity and quality (Hendrick W., 2000, Pg 23)

- The second, is specific micro-level approaches, it is the Advanced Manufacturing Technology.

These models can be applied to system design to improve safety, health, and performance (Katherine Donnelly, et al., 2005) 


\section{- Human -System Interface Technology [HSIT [}

The Human Factors and Ergonomics Society] HFES [Strategic Planning Steering Committee developed the HSIT to describe the" unique " technology of $\mathrm{HF} / \mathrm{E}$ that has been researched over the last 60 years. The HFES added standardization and control of systems to the above as application of ergonomics technology. Thus, ergonomics technology can then be applied to all stages of the design or modification of a system' to the design, analysis, test and evaluation, standardization, and control of systems.'According to the HFES the term technology refers to the design principles, guidelines, specifications, methods and tools that are developed by a discipline's science and used by its practitioners to accomplish some end (Hendrick W., 2000; Katherine Donnelly, et al., 2005(

\section{- Human-Environment Interface Technology [Environmental Ergonomics]}

The basic premise of the person-environment (PE) fit theory is that stress arises from a misfit between person and environment - not from the two components separately, but as the factors of each relate to one another. When individuals perceive that their work environments are not good, or do not fit well with the needs, wants, and desires that they personally would like fulfilled from work, the discrepancies create diverse strains, which are then hypothesized to affect workers 'health and wellbeing.

Environmental demands here include job requirements, role expectations, and group and organizational norms. Countering these demands are the individual's abilities represented through aptitudes, skills, training, time and energy the person uses to meet the demands. The idea is that the larger the discrepancy between person and environment, the greater the likelihood that strain, and a need for coping, will arise (Melanie Bickford, 2005)

\section{- Human-Machine Interface Technology [Hardware Ergonomics]}

As Hendrick W., 2000 has mentioned that The Error was the essential engine for ergonomists to develop the concept of "human-machine technology". Simply HMIF was still applying to biomechanical and anthropometric design parameters of controls, displays and workspace arrangements in industrial systems. To design in ways were compatible with human capabilities, limitations, and other characteristics. These findings led to research into better understanding of the human factors involved in 
designing human- machine interfaces and, hence, to the development of human factors as an identifiable area of research and application ,especially in RMGI. Today, safety and usability of a board spectrum of human machine system via design are going to consider all forms of transportation, industrial equipment and workstations.

\section{- Human/Software Interface Technology [Cognitive Ergonomics]}

Software-ergonomic standards contain three kinds of requirements, which concern:

- A product attributes .e.g. the number of maximum options in a menu panel؛

- An effect of task performance re.g. a selected menu option has to be indicated as being selected،

- A human outcome ee.g. the level of knowledge to be achieved through the use of a program.

In order to apply a standard it is necessary to interpret each requirement and identify its class. Different classes require different methods of conformance testing. Unfortunately. The Working Group 5 in IS0 TClSo/SCJ which developed the standards ignored a classification like this, since a general procedure of conformance testing has, as yet. Not been taken into account (Wolfgang Dzida, 1995.(

RMGIs have increased the usage of software's applications, such as computer-integrated manufacturing, computer-aided design and manufacture, and computer-numerical-controlled machines. These applications aim to achieve fitting between products and consumer requirements which have benefits to increase productivity and flexibility during product cycle in RMGIs (Mohamed El-Badry, 2004, pg. 104.(

\section{- User interface [UI]}

A good interface in RMG systems will not only minimize the possibility of user errors, but also be more tolerant towards the errors and boost the confidence level of the user. The strengths and weaknesses of the current DOS version of FDAS' [UI] are discussed along with ways of overcoming the drawbacks. (Sundaresan J., et al., 1991( 


\section{- Human/Job Interface Technology [Work Design Ergonomics.[}

Job design ergonomics has built on studying the technical of work methods and procedures to develop unique human-job technology. Intrinsically motivating, better utilize human capabilities, and avoid stressing human limitations, all of these parameters have been considered into developing work modules and combining modules into jobs with respect to such things as physical and mental workload (Hendrick W., 2000) Before designing human- machine system, the first stage to begin should be selecting aims and jobs in our RMGI (Abd El-Nabi, 2011 .)

\section{- Human/Organizational Interface Technology. [Macroergonomics.[}

While macroergonomics has been described as a top-down approach, Hendrick describes the human-organization interface technology dimension as not only being top-down, but also middle-out and bottom-up. The reason for this is that macroergonomics approaches should involve participation at all levels of the organization, not just from upper levels down (Katherine Donnelly, et al., 2005.(

As organizations perform this transformative process, they bring two factors to bear on the process: technology in the form of a technological subsystem, and people in the form of a personnel subsystem. The design of the technological subsystem primarily defines the tasks to be performed, whereas the design of the personnel subsystem prescribes the ways in which they are accomplished. Both interact at every human-machine and humansoftware interface. The technological and personnel subsystems thus are mutually interdependent. Both subsystems operate under joint causation in that they are affected because events in the external environment, for example, market competition or changes in government regulations or new materials (Michelle M. Robertson, 2001). The Macroergonomics is concerned with improving productivity and the quality of work life by an integration of psychosocial, cultural, and technological factors with humanmachine performance interface factors in the design of jobs, workstations, organizations, and related management systems (HFES)

\section{- Advanced Manufacturing Technology [AMT]}

A second micro-ergonomic approach to improve productivity, yet affects safety, in manufacturing organizations is AMT, as it serves to replace (or minimize) the human element in RMG tasks, making human 
operators passive monitors rather than active participants (Katherine Donnelly, et al., 2005, pg 140). AMT in RMG is relevant to operators' wages; this is why developed countries are going to apply AMT in the RMG because of the high wages of RMG operators. As these new technologies are introduced, it is necessary to determine their reflections on ergonomics consideration on RMGI.

AMT can be defined as the application of computer based systems to automate and integrate different functions in the manufacturing system, such as design, planning and manufacturing. Introducing AMT can significantly increase the complexity of operational systems, as the technologies used often serve multiple and flexibly interchangeable functions. The different parts of the system can also be highly interdependent. This means that the removal of a disturbance is more difficult, as a solution to a problem at one machine will need to be considered in relation to other parts of the system .

\section{- Evolution of Advanced Manufacturing Technology [AMT] in RMGI}

It is true that a number of semi- or fully automated technologies have been introduced on the RMGI such as spreading, nesting, marker making and cutting system and to a certain degree in the ironing and garment finishing processes (OECD, 2004). Despite this, major parts of handling and joining operations remain highly manual labour intensive making the whole garment making process uncompetitive in high operators' wages countries (Lutz Walter, et al. 2009). RMG manufacturing companies are exposed to tensions resulting from market demands, rapid technological development and social changes. Furthermore, today's customers often demand customized, high quality and competitively priced products with a timely delivery. These demands have put pressure on companies to produce garments' products with shorter life cycles, to produce a greater variety of styles, to adapt their manufacturing program to customers 'wishes within short time scales, and to produce smaller batch sizes in order to keep the finished stock as low as possible (Bradley C. and Waldemar K., 2003). This is why AMT was been entering RMGI as a better understood for an integrated system of the best human, organizational, and technological elements currently available (Alexia Barry $\mathrm{M}$ r.et al.(.

\section{- The Successful Use Of AMT Depends On:}

How the technology [e.g. computer-based technologies, information systems] is integrated with human factors [e.g. skill, expertise and cognition 
of users] and organisational factors [e.g. job design, human resource practices]. Conversely, a lack of integration can lead to poor outcomes, as it has reported that many manufacturing automation projects have failed because of insufficient automability (automation flexibility), inadequate user-system interfaces (i.e. human-computer integration (and an incompatibility between human needs and system requirements(Bradley $\mathrm{C}$. and Waldemar K., 2003)

\section{- Automation}

Automation has been defined as a device or system that performs a function previously performed by a human operator. However, automation does not simply supplant the person, but enables new activities, creates new roles for the person, and changes existing activities in unexpected ways. As a result, automation often produces surprises at many levels, from the societal, as with the (John D. Lee, et al. 2012). As a result 'the most important factors of man-machine interaction in AMT have been pointed in the paper. The attempt to propose the way of human modeling, decision quality and man-machine interaction description has been done and the socio-technical design idea was described. It can be very useful in designing of interactions of social and technical systems. For example, auxiliary and preparatory operations require $70 \%$ of the total production time, while sewing $30 \%$ of that time, when sewing garments at a rate of 3000-6000 stitches per minute. A period of auxiliary operations increases relatively by increasing the sewing speed to $8000+$ stitches per minute, but the increase in sewing productivity is negligible. In this case, a sewing machine operator physically cannot make auxiliary and preparatory operations at the required speed, and so slows down the whole garment production process (Alvydas Kondratas, 2005 .

The sewing efficiency depends on both high-speed sewing machines and the duration of manually executed operations and handling. Usually textile pieces that should be sewn together are handled by a worker. Handling includes picking up, conveying, fixing, and stretching, and so on. Due to subjective reasons such as experience, working conditions, fatigue and others, the efficiency of auxiliary operations also depends on the size of the pieces being sewn, the properties of their fabric (structure, thickness c stiffness, density, piling, etc.), gripping conditions, the way they are handled, and transportation direction. 


\section{- Grippers}

Robots are widely used together with the universal and specialized technical equipment. The application of industrial robots has resulted in an average increase in labour efficiency of $20 \%$ (and for sewing trousers, even as much as $420 \%$ ) and an improved quality of products

\section{- Engineering Ergonomics [EE]}

The New Encyclopedia Britannica, 1986 defines EE as; an application of information on physical and psychological characteristics to the design of devices and systems for human use. Its data and principles apply to activities of the home, the workplace, and recreation."(Deborah M., Donald, p. 31)

\section{- Engineering Ergonomics Challenges Integrate RMGI}

The RMGI is generally seen as a safe place to work, and when compared to other industries, there are relatively few serious accidents in RMG Factories. The hazards we face are different. The major health risks in this industry do not arise from immediate, potentially fatal hazards. Instead, the risks that RMG workers face come from more subtle hazards whose effect accumulates over time. Parameters such as repetition, force, posture and vibration are associated with higher rates of injury. But you can't look at the workstation alone to understand these injuries. There is growing evidence that other parameters are linked to injuries, some of these Parameters include high work pace, lack of control over the job, excessive workload, lack of co-worker support and general work environment. The Parameters that relate to reduced injury rates include empowerment of the workforce, safety protocols, and greater seniority of the workforce, good housekeeping and active role of top management (Saravanan K., et al. Jan.2011.(ILO 1991 ،consider the major engineering issues for provision healthy and efficient for the optimal human integration in workplaces, environments, and work conditions, are:

- Worker task position:

- Reach and grasp distances and orientation

- Working zones

- Lines of sight

- Work heights 


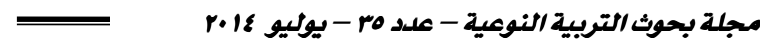

- Posture:

- All facets of working position

- Seated and standing work

- Furniture and equipment design

- Clearances:

- Access and fit

- Movement space

- Activity space

- Machine control:

- Control and handle dimensions, clearances, visibility

- force application:

- Allowable forces in certain postures

- Material handling

- Workstation layout:

- Display and control positions

- Display-control relationships

- Physical environment:

Lighting, noise, climate, vibration, radiation,chemical, psycho-social, spatial, etc) .Vittorio and Nigel C., 1998, pg. 49(

Factors such as good posture, suitable seats, table height, and good levels of ventilation, lighting, temperature and noise all combine in different ways to help a RMG worker to perform his work with efficiency and comfort. However, when such parameters are absent there may be less performance in production. One search seemed to be only marginally aware of how such workplace inadequacies might be relevant to garment production. Though, more than $90 \%$ of respondents each listed lighting, type of seats, table height and temperature as important for work, they did not explicitly relate the reasons they gave to ergonomic concerns. For example, color of wall surfaces, noise, ventilation and posture were each considered by some as even less important elements for their work (Vandyck, et al. 2014) 


\section{- Conclusion}

Building ergonomics awareness as a work culture is certainly the first phase to maximize RMG productivity, comfort, health, and safety, and to reduce injury, illness, and the likelihood of errors. The Harmonization and mutual adaptation between ergonomics parameters is a very complicated process. If these impacts are not anticipated and planned for, the result is likely to be a dysfunctional or suboptimal work system .

Applications of cognitive principles and constructs to the analysis of work-related problems, lead to rich new insights and intervention procedures for the enhancement of productivity and well-being at RMGI, such work scheduling, develop training programs and also assessment the work requirement as a continues process .Stakeholders in RMGI have really needs to work on fitting all elements together and to ensure harmony within all sociotechnical system component. Best practices of the technical and engineering ergonomics can provide a successful context for traditional ergonomics interventions and respective improvements. Finally, the perspective and parameters of ergonomics hold promise for large-scale change in RMGI by encouraging managers to better understand how improvements in working conditions are felt by workers .

\section{References}

- Abd El-Nabi Abu El-Magd, 2011".The Modern Ergonomics: Guide Lines For Human Factors in Design; Usability, Safety and Comfort", First Edition, AlRihaab City, New Cairo, Egypt.

- Alvydas Kondratas, 2005".Robotic Gripping Device for Garment Handling Operations and Its Adaptive Control", Fibres \& Textiles in Eastern Europe, Vol. 13, No. 4

- BCPE [Board of Certification in Professional Ergonomics" r . $.1 \%$ ، [Candidate Handbook: Certification- Policies, Practices \& Procedures", Fourth Edition Modified

- Bradley Chase and Waldemar Karwowski".r..r،CH.4: Advanced Manufacturing Technology"; the New Workplace: A Guide to the Human Impact of Modern Working Practices .David Holman, Toby D. Wall, Chris W. Clegg, Paul Sparrow and Ann Howard. C, John Wiley \& Sons, Ltd.

- Dan Magder, 2005" .Egypt after the Multi-Fiber Arrangement: Global Apparel and Textile Supply Chains as a Route for Industrial Upgrading", the Institute for International Economics, No. Wp 05^ -

- David Caple, 2007" .Ergonomics - Future Directions", J. Human Ergol., 36: 3136. 
- David J. Tyler, 2008" .Carr and Latham"s technology of clothing manufacture", 4th ed., Library of Congress Cataloging-in-Publication Data, ISBN: 978-1-40516198-5

- David Mijatovic, 2008" .Automotive parts industry-handbook on participatory ergonomics", Research Advisory Council of the Ontario Workplace Safety \& Insurance Board, and OHCOW.

- Deborah M. Licht \& Donald J. Polzella" .Human Factors, Ergonomics, and Human Factors Engineering \& an Analysis of Definitions", Crew System Ergonomics Information Analysis Center.

- Padmini D.S. and Venmathi A., sept. 2012".Unsafe Work Environment in Garment Industries, Tirupur, India", J. Environ. Res. Develop., 7 (1 A(

- Richard E.Clark, David F, et al., October 2006" .Cognitive Task Analysis ،"Final Draft

- Roger L. Brauer, 2006" .Safety and Health for Engineer- ch 33: ergonomics", Second Edition (C) ‘John Wiley \& Sons, Inc.

- Hendrick Hal W., 2000".The technology of ergonomics", Theor. Issues in ERGON. Sci., 1(1), 22-23

- HFES, access on: 2014 .http://www.hfes.org/web/TechnicalGroups/METG.pdf

- IEA, 2000" the Discipline of Ergonomics "www.iea.cc

- ILO\& IFC, Dec 2013".Research Brief: Improving Business Outcomes By Understanding What Matters To Workers"- Better work, Australian Government, Netherlands Ministry of Foreign Affairs, et al.

- Jan Dula, Ralph Bruder, et al" . r. I r ‘.A strategy for human factors/ergonomics: developing the discipline and profession", iFirst article: Taylor and Francis. Ergonomics, 1 r $v_{-}$

- John D. Lee and Bobbie D. Seppelt". r. Ir Chapter 59 :Human Factors and Ergonomics In Automation Design ،"Gavriel Salvendy" ‘Handbook of Human Factors and Ergonomics", Fourth Edition, John Wiley \& Sons, Inc.

- Juan Carlos Hiba, 1998" .Improving Working Conditions and Productivity in the Garment Industry", first published, ILO, ISBN 92-2-110849-X

- Katherine A. Wilson-Donnelly, et al., 2005".The Impact of Organizational Practices on Safety in Manufacturing: A Review and Reappraisal", Human Factors and Ergonomics in Manufacturing, Wiley Periodicals c $1 V \tau_{-} / T_{0}(r) 10$ ، DOI: $10.1002 / \mathrm{hfm} .20000$

- Laura G. Militello, Cynthia O. Dominguez, et al., 2009" .The Role of Cognitive Systems Engineering In The Systems Engineering Design Process", Systems Engineering, Wiley Periodicals, Inc, 13(3(

- Lutz Walter, George-Alexander and Stefano Carosio, 2009".Transforming Clothing Production into a Demand driven, Knowledge-based, High-tech Industry", British Library, Springer-Verlag London Limited, ISBN 978-1-84882607-6 
- Mai Samir Ali, 2008".Study the Effecting Factors of Labor Performance Efficiency in the Apparel Factories through Ergonomics", Master Study, Faculty of Applied Arts, Helwan University.

- Melanie Bickford" . . . • ‘Stress in the Workplace: A General Overview of the Causes, the Effects, and the Solutions", Canadian Mental Health Association, Newfoundland and Labrador Division

- Michelle M. Robertson, 2001".Macroergonomics: A Work System Design Perspective", Proceedings of The Self-Ace 2001 Conference - Ergonomics For Changing Work.

- Michael Stein and Peter Sandl, 2012" .Information Ergonomics- A Theoretical Approach and Practical Experience in Transportation", Springer-Verlag Berlin Heidelberg, ISBN 978-3-642-25840-4] Michael Herczeg And Michael Stein ، Human Aspects Of Information Ergonomics]\&[Heiner Bubb ‘nformation Ergonomics[

- Mohamed El-Badry, 2004".The Intelligence of sewing machines", National Center for Research, Cairo, Egypt.

- NSDC raccess on: 30/6/2014" .Qualifications Pack - Sewing Machine Operator", Qualifications Pack - Occupational Standards for Apparel, Made-Up's And Home Furnishing Sector http://www.nsdcindia.org/pdf/Sewing-MachineOperator-Qualification-Pack-Final-31Mar14.pdf

- OECD, 2004".A New World Map in Textiles and Clothing: Adjusting to Change", ISBN-92-64-9264018530

- Saravanan K. and Kumaraguru, January 2011".Importance and need of ergonomics in the apparel industry", Apparel \& Knitwear PTJ 57-58

- Skilltran, 2003-2008" .Pocket Guide to The Dictionary of Occupational Titles (DOT) and the Characteristics of Occupations " SkillTRAN LLC-Spokane Valley, WA .www.skilltran.com

- Sundaresan Jayaraman, et al., 1991".Analysis Of Defects In Trouser Manufacturing: Development of A Knowledge-Based Framework", Defense Logistics Agency, Georgia Institute of Technology, School of Textile \& Fiber Engineering, Vol. I :Final Technical Report

- U.S. Department Of Labor, 1991" .Chapter 1 Job Analysis: What It Is and Its Uses", Revised Handbook For Analyzing Jobs, Washington, DC: Government Printing Office ‘http://online.skilltran.com/rhaj/chapter1.htm

- Vandyck E., Tackie-Ofosu V., et al., 2014" .Effects of ergonomic practices on garment production in Madina, Ghana". Int. Res. J. Arts Soc. Sci. 3(1):1-7

- Vittorio Di Martino and Nigel Corlett, 1998".Work Organization and Ergonomics", ILO ‘Geneva, ISBN 92-2-10951 8-5

- Waldemar Karwowski, 2006" .Handbook of Human Factors and Ergonomics", Third Edition, Chapter 1-The Discipline of Human Factors and Ergonomics, John Wiley \& Sons, Inc. 
- Wendy Macdonald, 2003" .The Impact of Job Demands and Workload on Stress And Fatigue", Australian Psychologist, 38(2):102-117

- White Queen Safety Strategies \& Environmental Resources Management, 2007 . "Development of a working model of how human factors, safety management systems and wider organisational issues fit together", Health and Safety Executive.

- Wolfgang Dzida, 1995" .Standards for user-interfaces", Computer Standards \& Interfaces, 17, pg.89-97

- Zainab Abd El-Majid and Abeer hamdy". . . 9 ‘Study the implementation of ergonomics in apparel industry in Egypt ${ }^{\top}$ ،"th International Conference of Textile Research Division, state of the Art \& future developments, National Center for Research, Cairo, Egypt.

- Zainab Abd El-Majid, Hasn Abd El-Aal and Abeer Hamdy, 2009".the ergonomic designing solutions to face the constraints of apparel industry in Egypt", 6th International Conference of Textile Research Division, state of the Art \& future developments, National Center for Research, Cairo, Egypt. 


\section{تأثير عوامل الإرجونوهيكس على صناءة الملابس الجاهزة \\ دراسة تحليلية \\ الملخص العربي}

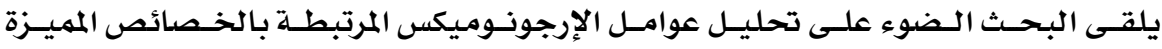

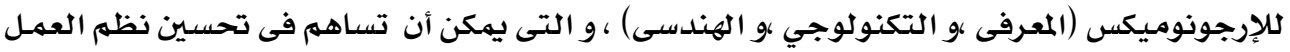

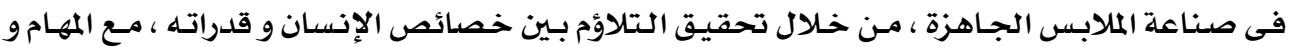

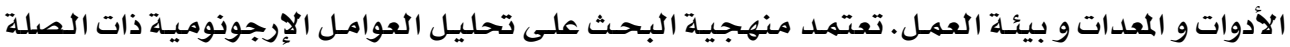

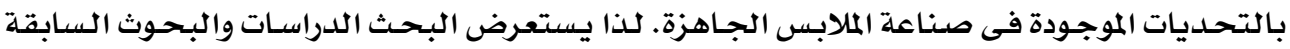

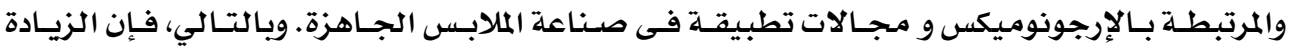

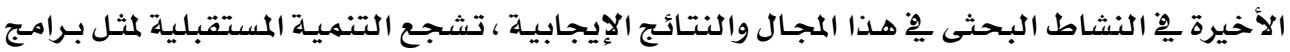

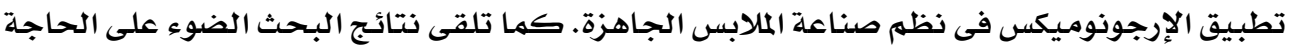

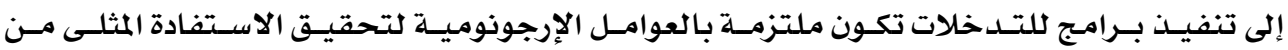
نظم العمل.

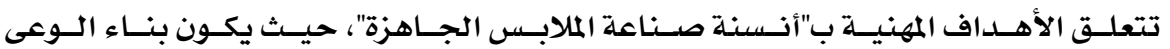
الإرجونومى ؛ هو بالتأكيد المرحلة الأولى من العملية الإرجونوميلة. 